\title{
Sizing of STATCOM to Enhance Voltage Stability of Power Systems for Normal and Contingency Cases
}

\author{
Heba A. Hassan ${ }^{1,2 *}$, Zeinab H. Osman², Abd El-Aziz Lasheen ${ }^{3}$ \\ ${ }^{1}$ Electrical and Computer Engineering Department, Dhofar University, Salalah, Oman; ${ }^{2}$ Electrical Power and Machines Department, \\ Cairo University, Giza, Egypt; ${ }^{3}$ Electricity Holding Company, Ministry of Electricity and Energy, Cairo, Egypt. \\ Email: "hebahassan@ieee.org
}

Received November $30^{\text {th }}, 2013$; revised December $30^{\text {th }}$, 2013; accepted January $7^{\text {th }}, 2014$

Copyright (C) 2014 Heba A. Hassan et al. This is an open access article distributed under the Creative Commons Attribution License, which permits unrestricted use, distribution, and reproduction in any medium, provided the original work is properly cited. In accordance of the Creative Commons Attribution License all Copyrights (C) 2014 are reserved for SCIRP and the owner of the intellectual property Heba A. Hassan et al. All Copyright (C) 2014 are guarded by law and by SCIRP as a guardian.

\section{ABSTRACT}

The electric power infrastructure that has served huge loads for so long is rapidly running up against many limitations. Out of many challenges it is to operate the power system in secure manner so that the operation constraints are fulfilled under both normal and contingent conditions. Smart grid technology offers valuable techniques that can be deployed within the very near future or which are already deployed nowadays. Flexible AC Transmission Systems (FACTS) devices have been introduced to solve various power system problems. In literature, most of the methods proposed for sizing the FACTS devices only consider the normal operating conditions of power systems. Consequently, some transmission lines are heavily loaded in contingency case and the system voltage stability becomes a power transfer-limiting factor. This paper presents a technique for determining the proper rating/size of FACTS devices, namely the Static Synchronous Compensator (STATCOM), while considering contingency cases. The paper also verifies that the weakest bus determined by eigenvalue and eigenvectors method is the best location for STATCOM. The rating of STATCOM is specified according to the required reactive power needed to improve voltage stability under normal and contingency cases. Two case system studies are investigated: a simple 5-bus system and the IEEE 14-bus system. The obtained results verify that the rating of STATCOM can be determined according to the worst contingency case, and through proper control it can still be effective for normal and other contingency cases.

\section{KEYWORDS}

\section{STATCOM; Voltage Stability; Contingency; Eigenvalues and Eigenvectors; Newton-Raphson Load Flow}

\section{Introduction}

In a competitive energy market, the grid mostly operates very close to its maximum capacity. Therefore, congestions may occur due to unexpected line outage, generator outage, sudden increase of demand, failures of equipments, etc. Hence, network congestion has become a major concern for smart grids. However, in the context of the smart grid, it is possible to obtain measurements throughout the grid to identify and implement the necessary control actions in sub-second time frames. Thus, voltage instability and collapse that may lead to the blackout can be avoided, if suitable monitoring is used

${ }^{*}$ Corresponding author. and application of a preventive control is taken. In this context, FACTS devices can be applied to improve the voltage stability of power systems.

One of the most recent technologies that has always grasped the attention of researchers in power engineering is the Flexible AC Transmission System (FACTS). This technique appeared in literature for the first time in 1989 when Narian Hingorani defined FACTS as "The concept of using solid-state power electronic devices mainly thyristor for power flow control at transmission level", [1]. Recent advances in the area of voltage source converters (VSC) have also added to this area of research. In addition, there is an increasing interest in using FACTS devices in the operation and control of power systems. 
These devices are characterized by fast response, high reliability and wide operating range [2-5].

Voltage stability is a problem in power systems which are heavily loaded, faulted or have a shortage of reactive power. The nature of voltage stability can be analyzed by examining the production, transmission and consumption of reactive power. The problem of voltage stability concerns the whole power system, although it usually has a large involvement in one critical area of the power system. The voltage stability can be improved by allocating FACTS devices [6-13].

The contingency ranking methods for voltage stability analysis are based on sensitivities of voltage stability margin, the curve fitting method, simultaneous computation of multiple contingency cases and parallel/distributed computation algorithms [14-17]. The state of power system voltage stability can be described in terms of reactive power losses [18]. When the power system is stressed, reactive power losses increase compared to the operation point. In this case, the reactive power losses of outages need to be calculated and the ranking of contingencies can be directly based on them.

The minimum singular value of the load-flow Jacobian matrix is zero at the voltage collapse point, [19,20]. It is used as an indicator to quantify proximity to post disturbance maximum loading point. The use of the indicator requires the computation of post-disturbance load flows for each outage. The value of the minimum singular value of the load flow Jacobian matrix is also sensitive to limitations and changes of the reactive power output. Computing the minimum singular values at the stressed operation point can increase the accuracy of the method.

This paper presents an algorithm to determine the rated capacity of STATCOM to improve the static voltage stability of a power system under normal and contingency conditions. This is achieved through rescheduling the reactive power control variables of STATCOM. The algorithm utilizes the method of the eigenvalues and eigenvectors of the load flow Jacobian which is a proximity indicator that determines the weakest bus in the system. The rating of STATCOM is proposed to be determined while taking into account its suitability for both normal and contingency cases. Section 2 overviews the basic structure and operation theory of STATCOM. In Section 3, the saddle-node bifurcation and system voltage instability are explained. Section 4 presents the algorithm of the developed technique and MATLAB package for the optimal allocation of STATCOM. Results of two case-studies are presented in Section 5 for a 5-bus system model and IEEE 14-bus power system. The given results included system study and load flow analysis under normal operating conditions and in case of contingencies with and without STATCOM after the implementation of the developed device allocation technique. The main conclusions and contribution of the paper are mentioned in Section 6.

\section{STATCOM Device}

STATCOM is a static synchronous generator operated as a shunt connected static VAR compensator whose capacitive or inductive output current can be controlled independent of the AC system voltage. Figure 1 shows a simple diagram of the STATCOM based on a voltage sourced converter. For the voltage source converter, its ac output voltage is controlled, such that, it is just right for the required reactive current flow for any ac bus voltage, and DC capacitor voltage is automatically adjusted as required to serve as a voltage source for the converter. The basic operational principle of STATCOM is as follows:

- The voltage source converter which is connected to a DC capacitor generates a controllable AC voltage source behind the transformer.

- The voltage difference across the reactance of the transformer produces active and reactive power exchanges between the STATCOM and the power system.

- The STATCOM output voltage magnitude can be controlled by controlling the voltage across the DC capacitor.

\section{Saddle-Node Bifurcation (SNB) and Static Voltage Instability}

A saddle-node bifurcation is the disappearance of system equilibrium as parameters change slowly. The saddlenode bifurcation has been shown as SNB point in the voltage $(\mathrm{V})$ versus the loading factor $(\lambda)$ curve as in Figure 2. In this figure, there are two voltage solutions before saddle-node bifurcation point, for certain loading factors. The upper voltage solution corresponds to normal behaviour of power system and represents stable

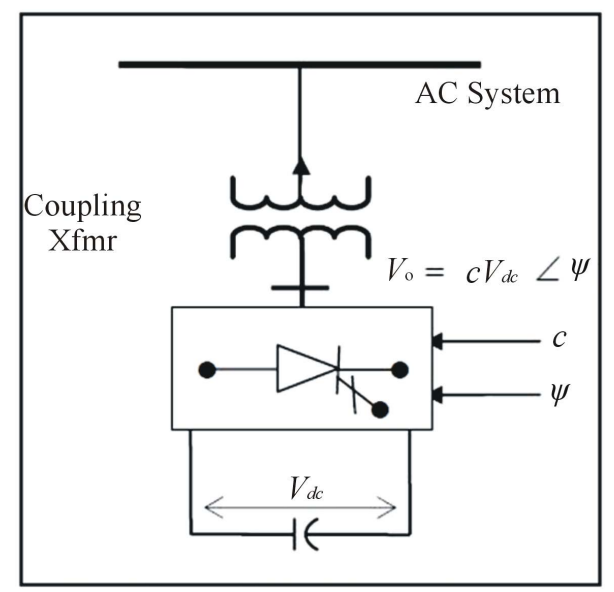

Figure 1. Basic structure of STATCOM. 


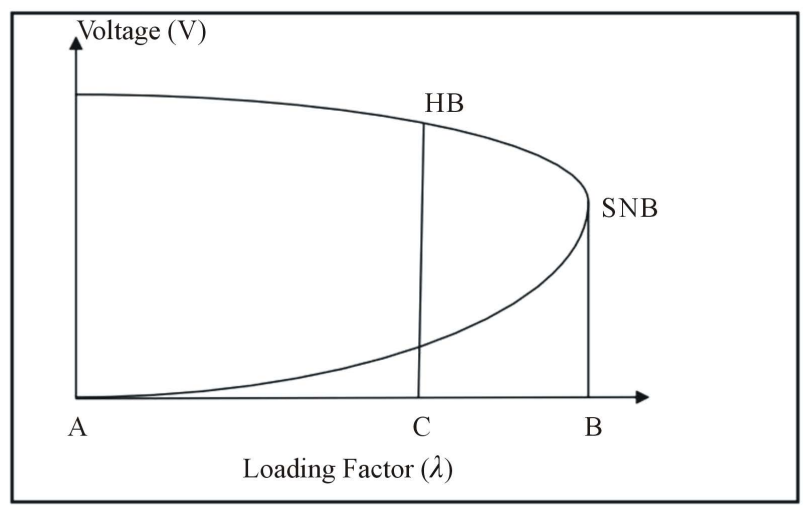

Figure 2. Saddle-node bifurcation and Hopf bifurcation.

solution. The lower voltage solution represents unstable solution as all controllers designed for voltage control fail and a progressive decay of voltage occurs.

At the saddle-node bifurcation point, only one voltage solution occurs and beyond SNB no solution exists. Hence, the system can be loaded up to the SNB point. Therefore, SNB point is also called the maximum loadability point. The saddle-node bifurcation occurs due to slow and gradual increase in loading and may result in static voltage instability. The horizontal distance between the base case operating point and the saddle-node bifurcation point, which is the distance $\mathrm{AB}$, as shown in Figure 2 , is called the static voltage stability margin or static loading margin, whereas the distance AC represents the oscillatory voltage stability margin or the dynamic loading margin.

The power system may be represented by a static model where, static load flow equations may be solved at different loadings to determine the saddle-node bifurcation point. At SNB point, the sensitivity $\partial V / \partial \lambda$ becomes infinity and Newton-Raphson Load Flow Jacobian becomes singular.

\section{Algorithm of the Developed Method}

The equation of saddle-node bifurcation can be solved by Newton-Raphson iterative technique. The use of Newton-Raphson method requires good initial values in order to converge to the bifurcation point. When applying the point of collapse method to voltage stability analysis, the information included in the eigenvectors can be used in the analysis of voltage stability. The right eigenvector defines the buses close to voltage collapse. The biggest element in magnitude of the right eigenvector shows the most critical bus.

The sizing criterion of STATCOM is determined by the value that partially compensates the reactive power, while the voltage at any bus of the system does not exceed the allowable limit. The placement criterion of STATCOM is to have it connected at the weakest bus of the system.

The developed algorithm can be summarized through the following steps:

Step 1: Formulate $Y_{\text {bus }}$ in per unit.

Step 2: Assign initial values to the unknown voltage magnitudes and angles of all system buses.

Step 3: Determine the mismatch vector for Iteration $k$.

Step 4: Determine the Jacobian matrix $(J)$ for Iteration $\mathrm{k}$.

Step 5: Determine the error vector $(\Delta X)$, then set $X$ at iteration $(k+1)$ such that $X^{(k+1)}=X^{(k)}+\Delta X^{(k)}$, and check if the power mismatches are within tolerance, [10]. If so, go to Step 6, otherwise go back to Step 3 .

Step 6: Compute the line current flows as well as the active and reactive line losses.

Step 7: Increase the load demand and compute the voltage until reaching the SNB, as given in Appendix A.

Step 8: Compute the system eigenvalues and right eigenvectors to determine the weakest bus.

Step 9: Connect the STATCOM at the weakest bus.

Step 10: Solve the load flow problem with STATCOM erected at the weakest bus while considering that the operating constraints are not violated, and determine the required STATCOM rating.

\section{Simulation Results of Case Studies}

\subsection{Application on 5-Bus System}

The data of the 5-bus system, whose single line diagram is illustrated in the Appendix B, are detailed in [11] and [21]. The system consists of a slack bus (1), a PV bus (2) with limited values of reactive power in both lagging and leading case, and PQ buses (3-5). Table 1 illustrates the load flow solution under normal operating conditions (base case). Under these conditions, a large amount of reactive power generation (90.82 MVAR) is demanded by the generator connected to the slack bus. This amount is well in excess of the reactive power drawn by the system loads (40 MVAR). The generator connected to PV bus draws the excess of reactive power in the network which is 61.59 MVAR. This amount includes the net

Table 1. Newton-Raphson load flow solution of 5-bus system (Base case).

\begin{tabular}{ccccccc}
\hline \multirow{2}{*}{ Bus No. } & \multirow{2}{*}{$\begin{array}{c}\text { Voltage } \\
\text { (p.u.) }\end{array}$} & Angle & \multicolumn{2}{c}{ Generation } & \multicolumn{2}{c}{ Load } \\
\cline { 5 - 7 } & & Degree & MW & MVAR & MW & MVAR \\
\hline 1 & 1.060 & 0 & 131.12 & 90.81 & 0 & 0 \\
2 & 1.000 & -2.0 & 40 & -61.59 & 20 & 10 \\
3 & 0.987 & -4.6 & 0 & 0 & 45 & 15 \\
4 & 0.984 & -4.9 & 0 & 0 & 40 & 5 \\
5 & 0.971 & -5.7 & 0 & 0 & 60 & 10 \\
Sum & & & 171.122 & 29.22 & 165 & 40 \\
\hline
\end{tabular}


reactive power produced by several transmission lines. These results are given in [21] which verify the output data obtained from the developed MATLAB software program.

Figure 3 shows that by increasing the initial value of load $P_{D_{\text {io }}}$ at all system load buses $\left(P_{D_{i}}=P_{D_{\text {io }}}+\lambda P_{\Delta \text { Pbase }}\right)$, without any compensation applied and based on constant power factor load increase, the voltage collapse at the saddle-node bifurcation is determined. The loading factor $\lambda$ is 2.98. It is known that this loading point is only a theoretical point and it is calculated to determine the load flow Jacobian matrix at that point and the margin to voltage stability point. Table 2 summarizes the load flow results of the system at the maximum loading point (SNB).

The values of active and reactive powers exceed the generators limits. The eigenvalues and eigenvectors of the system near this singularity of the Jacobian matrix at $\lambda=2.98$ are calculated.

Table 3 illustrates the eigenvalues and eigenvectors of the Jacobian matrix at the bifurcation point calculated by the developed MATLAB software package. From this table, it is clear that at $\lambda=2.98$, there is a critical eigenvalue whose value approximately tends to zero with

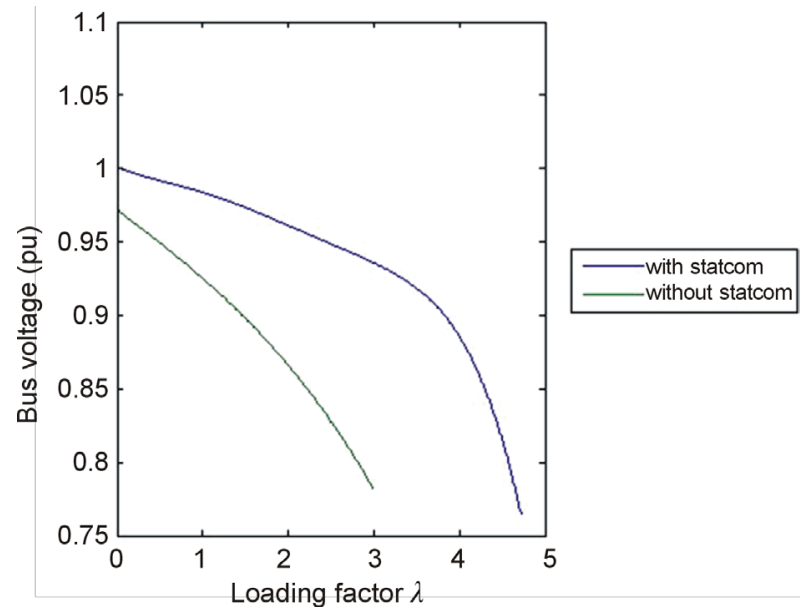

Figure 3. Loading factor with and without STATCOM erected at bus 5 .

Table 2. Newton-Raphson load flow solution at critical loading of 5-bus system.

\begin{tabular}{ccccccc}
\hline \multirow{2}{*}{ Bus No. } & \multirow{2}{*}{$\begin{array}{c}\text { Voltage } \\
\text { (p.u.) }\end{array}$} & \multirow{2}{*}{$\begin{array}{c}\text { Angle } \\
\text { Degree }\end{array}$} & \multicolumn{2}{c}{ Generation } & \multicolumn{2}{c}{ Load } \\
\cline { 4 - 7 } & & MW & MVAR & MW & MVAR \\
\hline 1 & 1.06 & 0 & 761.6 & 90.9 & 0 & 0 \\
2 & 1.00 & -18.5 & 40 & 478.7 & 79.6 & 39.8 \\
3 & 0.81 & -28.3 & 0 & 0 & 179.1 & 59.7 \\
4 & 0.81 & 1 & 0 & 0 & 159.2 & 19.9 \\
5 & 0.78 & -36.3 & 0 & 0 & 238.8 & 39.8 \\
Sum & & & 801.6 & 569.6 & 656.7 & 159.2 \\
\hline
\end{tabular}

minimum value of 2.19, and hence, it approaches the bifurcation point. By investigating the maximum magnitude of the eigenvector components corresponding to that minimum critical eigenvalue, it is clear that the maximum magnitude occurs at bus 5 , hence bus 5 is the weakest bus to which STATCOM will be connected.

To verify that bus 5 is the optimal bus for compensation, the STATCOM is allocated at buses 3, 4 then bus 5, taken into consideration that the terminal bus voltage values are within the permissible limits (0.98 - 1.06 p.u.) under normal loading conditions. A comparison among these three cases is performed to verify the validity of the obtained results. Table 4 summarises the results of allocating STATCOM at buses 3, 4, and 5 .

It is clear that when the STATCOM is allocated at bus 5 , the new loading factor $\lambda$ reaches 4.71 . Hence, the maximum loadability point is increased from 2.98 to 4.71 . With STATCOM erected at bus 5, the maximum loading is increased and at the same time the bus voltages are within acceptable limits in normal operation. Table 5 illustrates the voltage magnitude of each of the 5 buses after erecting STATCOM of rating 33.344 MVAR at bus 5 , where all the voltages are within limits.

Table 3. Eigenvalues and Eigenvectors of the Jacobian matrix of 5-bus system.

\begin{tabular}{ccccc}
\hline \multirow{2}{*}{ Eigenvalues } & \multicolumn{4}{c}{ Eigenvectors } \\
\cline { 2 - 5 } & Bus 2 & Bus 3 & Bus 4 & Bus 5 \\
\hline 50.13 & 0.011 & -0.71 & 0.70 & -0.05 \\
30.98 & -0.97 & 0.10 & 0.17 & 0.15 \\
2.19 & -0.32 & -0.49 & -0.53 & $-\mathbf{0 . 6 1}$ \\
8.67 & 0.027 & -0.48 & -0.45 & 0.75 \\
\hline
\end{tabular}

Table 4. Results of placement of STATCOM at buses 3, 4, and 5.

\begin{tabular}{cccccc}
\hline Bus No. & 1 & 2 & 3 & 4 & 5 \\
\hline $\begin{array}{c}\text { V in critical case } \\
\text { (p.u.) }\end{array}$ & 1.06 & 1 & 0.8083 & 0.8068 & 0.7826 \\
$\begin{array}{c}\text { V with STATCOM } \\
\text { at bus 3 (p.u.) }\end{array}$ & 1.06 & 1 & 1.0000 & 0.9968 & 0.9760 \\
$\begin{array}{c}\text { V with STATCOM } \\
\text { at bus 4 (p.u.) }\end{array}$ & 1.06 & 1 & 1.0002 & 1.0000 & 0.9774 \\
$\begin{array}{c}\text { V with STATCOM } \\
\text { at bus 5 (p.u.) } \\
\begin{array}{c}\text { STATCOM in } \\
\text { (MVAR) }\end{array}\end{array}$ & 1.06 & 1 & 0.9927 & 0.9911 & 1.0000 \\
$\quad$ New $\lambda$ & & & 25.995 & 26.682 & 33.344 \\
\hline
\end{tabular}

Table 5. Voltage profile after erecting STATCOM at bus 5 in p.u.

\begin{tabular}{ccccc}
\hline $\mathrm{V}_{1}$ & $\mathrm{~V}_{2}$ & $\mathrm{~V}_{3}$ & $\mathrm{~V}_{4}$ & $\mathrm{~V}_{5}$ \\
\hline 1.06 & 1.0 & 0.9927 & 0.9911 & 1.0000 \\
\hline
\end{tabular}


The load flow analysis is then carried out by considering one-line outage contingency at a time. The required STATCOM rating for different contingencies is given in Table 6. The biggest value of STATCOM rating corresponds to the outage of line 5 for this case study. The magnitude of the voltage at bus 5 is noticed to be within permissible limits in each contingency case.

Table 7 illustrates the voltage magnitude at bus 5 before and after erecting STATCOM at bus 5 during various cases of contingency.

From Table 7, it is clear that the voltage at bus 5 is greater in case of contingency with STATCOM erected at bus 5 than without STATCOM. That is due to the increase of MVAR injected by STATCOM in case of contingency. In summary, STATCOM of rating 40 MVAR and erected at bus 5 can lead to an acceptable voltage profile for normal and contingency cases. In other words, the rating of STATCOM is increased from 33.34 MVAR to 40 MVAR to suit both normal and contingency cases, therefore the control of STATCOM output reactive power is carried out to adapt the operating conditions of the power system.

\subsection{Application on IEEE 14-Bus System}

In order to verify the effectiveness of the proposed sizing and allocating algorithm of FACTS device, the IEEE 14-bus test system, whose single line diagram is shown in the Appendix B, is also considered. It consists of five synchronous machines; three of which are synchronous compensators used only for reactive power support. There are 11 loads in the system consuming total active and reactive powers of $259 \mathrm{MW}$ (2.59 p.u.) and 77 MVAR (0.77 p.u.). The active and reactive power losses are 15.67 MW and 12.76 MVAR respectively. The voltage magnitude at the slack bus is considered equal to 1

Table 6. STATCOM rating in MVAR for different line outages.

\begin{tabular}{ccccccc}
\hline Line 1 & Line 2 & Line 3 & Line 4 & Line 5 & Line 6 & Line 7 \\
\hline 35.42 & 37.54 & 34.51 & 35.03 & 39.94 & 35.13 & 33.87 \\
\hline
\end{tabular}

Table 7. Voltage at bus 5 before and after erecting STATCOM at bus 5 during contingency.

\begin{tabular}{ccc}
\hline Outage Line & $\begin{array}{c}\mathrm{V}_{5} \text { without } \\
\text { STATCOM (p.u.) }\end{array}$ & $\begin{array}{c}\mathrm{V}_{5} \text { with } \\
\text { STATCOM (p.u.) }\end{array}$ \\
\hline Line 1 (1-2) & 0.9679 & 0.9983 \\
Line 2 (1-3) & 0.9634 & 0.9962 \\
Line 3 (2-3) & 0.9687 & 0.9991 \\
Line 4 (2-4) & 0.9672 & 0.9986 \\
Line 5 (2-5) & 0.8579 & 0.9941 \\
Line 6 (3-4) & 0.9662 & 0.9985 \\
Line 7 (4-5) & 0.9618 & 1.0000 \\
\hline
\end{tabular}

p.u. to study the effect of SATCOM on the voltage profile and stability of the system model. It is well known that additional improvement can be achieved by increasing also the voltage of the slack bus. However, in this paper the effect of using STATCOM is studied.

Table 8 summarizes the results of the load flow solution under full load condition (base case). The voltage magnitude at each of the buses 13 and 14 is less than the minimum permissible value considered in this case study which is 0.95 p.u.

Table 9 shows that by increasing the load at system load buses, based on constant power factor load increase, the voltage collapse at the saddle-node bifurcation point is reached. The critical $\lambda$ value is equal to 2.42 , and the load ratio of critical case to base case is equal to 3.42 as illustrated in Figure 4. Most load buses have voltages magnitudes which are less than 0.95 p.u. The lowest value of the voltage magnitude is at bus 14 which is 0.586 p.u. Active power loss is equal to $482.3 \mathrm{MW}$ while the reactive power loss is 1871.07 MVAR.

Table 10 shows the eigenvalues and eigenvectors at the critical loading condition of $\lambda$ equals to 2.42 . It is clear that at this critical loading factor there is an eigenvalue which is equal to 0.02106 which approximately tends to zero. Hence, the bifurcation point is reached. By tracing the magnitudes of the eigenvector components corresponding to this minimum eigenvalue, it is found that the maximum magnitude is 0.54556 which occurs at bus 14 . Hence, bus 14 is the weakest bus. Therefore, the STATCOM is to be located at bus 14 .

Table 11 presents the load flow analysis of the system while having the STATCOM erected at bus 14 in order to maintain all bus voltages within the permissible limits. Total active power loss and reactive power loss are equal to $15.646 \mathrm{MW}$ and 11.7 MVAR, respectively. Consequentl, one STATCOM device is sufficient to be placed at bus 14 in order to regulate the voltage magnitude at

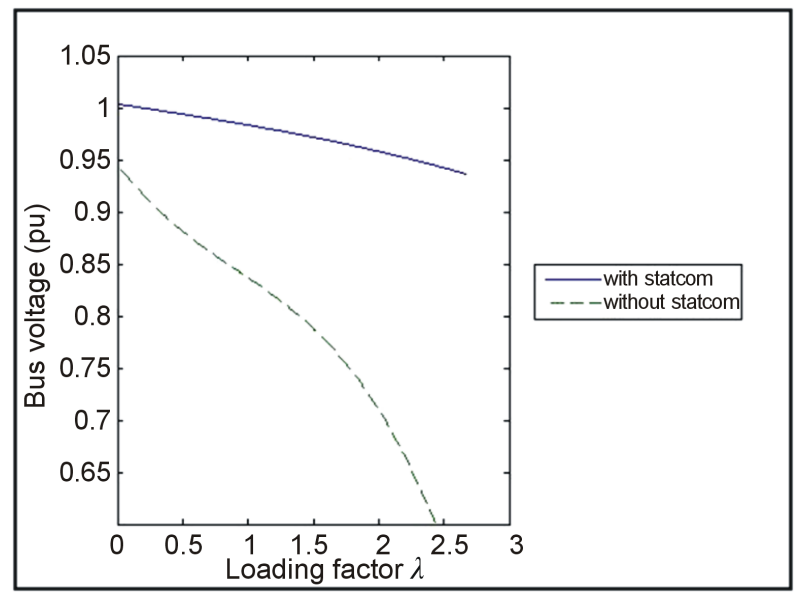

Figure 4. Loading factor with and without STATCOM erected at bus 14 . 
Table 8. Newton-Raphson load flow solution of IEEE 14-bus system (Base case).

\begin{tabular}{|c|c|c|c|c|c|c|}
\hline \multirow{2}{*}{ Bus No. } & \multirow{2}{*}{ Voltage (p.u.) } & \multirow{2}{*}{$\begin{array}{l}\text { Angle } \\
\text { Degree }\end{array}$} & \multicolumn{2}{|c|}{ Generation } & \multicolumn{2}{|c|}{ Load } \\
\hline & & & MW & MVAR & MW & MVAR \\
\hline 1 & 1.0 & 0.0 & 234.761 & -54.558 & 0 & 0 \\
\hline 2 & 1.0000 & -5.8 & 40 & 71.153 & 21.7 & 12.7 \\
\hline 3 & 0.9700 & -14.6 & 0 & 39.219 & 94.2 & 19 \\
\hline 4 & 0.9522 & -11.5 & 0 & 0 & 47.8 & 0 \\
\hline 5 & 0.9764 & -9.9 & 0 & 0 & 7.6 & 1.6 \\
\hline 6 & 0.9700 & -16.4 & 0 & 20.402 & 11.2 & 7.5 \\
\hline 7 & 0.9754 & -15.1 & 0 & 0 & 0 & 0 \\
\hline 8 & 1.0000 & -15.1 & 0 & 13.948 & 0 & 0 \\
\hline 9 & 0.9579 & -17.1 & 0 & 0 & 29.5 & 16.6 \\
\hline 10 & 0.9518 & -17.3 & 0 & 0 & 9 & 5.8 \\
\hline 11 & 0.9570 & -17.1 & 0 & 0 & 3.5 & 1.8 \\
\hline 12 & 0.9538 & -17.4 & 0 & 0 & 6.1 & 1.6 \\
\hline 13 & 0.9488 & -17.5 & 0 & 0 & 13.5 & 5.8 \\
\hline 14 & 0.9339 & 18.5 & 0 & 0 & 14.9 & 5 \\
\hline Sum & & & 274.671 & 90.164 & 259 & 77.4 \\
\hline
\end{tabular}

Table 9. Newton-Raphson load flow solution at critical loading of IEEE 14-bus system.

\begin{tabular}{|c|c|c|c|c|c|c|}
\hline \multirow{2}{*}{ Bus No. } & \multirow{2}{*}{ Voltage (p.u.) } & \multirow{2}{*}{$\begin{array}{c}\text { Angle } \\
\text { Degree }\end{array}$} & \multicolumn{2}{|c|}{ Generation } & \multicolumn{2}{|c|}{ Load } \\
\hline & & & MW & MVAR & MW & MVAR \\
\hline 1 & 1.0000 & 0.0 & 1328.08 & 207.061 & 0.0 & 0.0 \\
\hline 2 & 1.000 & -37.0 & 40 & 1022.44 & 74.214 & 43.434 \\
\hline 3 & 0.9500 & -82.0 & 0 & 420.691 & 322.164 & 64.98 \\
\hline 4 & 0.6743 & -67.1 & 0 & 0 & 163.476 & 0.0 \\
\hline 5 & 0.6778 & -57.3 & 0 & 0 & 25.992 & 5.472 \\
\hline 6 & 0.9500 & -104.6 & 0 & 357.452 & 38.304 & 25.65 \\
\hline 7 & 0.7124 & -90.2 & 0 & 0 & 0 & 0 \\
\hline 8 & 0.9500 & -90.2 & 0 & 128.146 & 0 & 0 \\
\hline 9 & 0.6189 & -103.6 & 0 & 0 & 100.89 & 56.772 \\
\hline 10 & 0.6361 & -106.1 & 0 & 0 & 30.78 & 19.836 \\
\hline 11 & 0.7740 & -105.8 & 0 & 0 & 11.97 & 6.156 \\
\hline 12 & 0.8597 & -108.9 & 0 & 0 & 20.862 & 5.472 \\
\hline 13 & 0.8124 & -109.0 & 0 & 0 & 46.17 & 19.836 \\
\hline 14 & 0.5860 & -115.3 & 0 & 0 & 50.958 & 17.1 \\
\hline Sum & & & 1368.08 & 2135.78 & 885.78 & 264.708 \\
\hline
\end{tabular}

this bus and keep it within the permissible limit. In this case, the STATCOM generates 23.578 MVAR.

Figure 4 depicts the magnitude of the bus voltage in per unit versus the loading factor $\lambda$ for the base case and with the STATCOM erected at bus 14. It is clear, that the value of critical loading factor has increased to 2.66.

Power systems engineers should have the operating power system secure, i.e. the system is able to withstand the failure of any equipment. Hence, the need for con- tingency analysis arises to checks the security of the system. Therefore, this research work presents a study of allocating STATCOM in the system while taking into consideration different cases of contingency. The developed software package is able to introduce the outage of a line one-by-one, provide the power flow analysis for each case, and then check the magnitude of the voltage at each bus. The rating of STATCOM, for each contingency case, is given in Table 12. 
Table 10. Eigenvalues and Eigenvectors of the Jacobian matrix of IEEE 14-bus system.

\begin{tabular}{|c|c|c|c|c|c|c|c|}
\hline \multirow{2}{*}{ Eigenvalues } & \multicolumn{7}{|c|}{ Eigenvectors } \\
\hline & Bus 1 & Bus 3 & Bus 4 & Bus 5 & Bus 6 & Bus 7 & Bus 8 \\
\hline 29.08193 & 0.08077 & -0.84936 & 0.18699 & -0.04492 & -0.00067 & 0.10949 & -0.07930 \\
\hline 19.45788 & 0.72681 & 0.32547 & 0.01492 & 0.01196 & 0.02465 & 0.11908 & -0.42082 \\
\hline 15.81450 & -0.65379 & 0.09323 & 0.02271 & -0.08550 & -0.00897 & 0.24582 & -0.52034 \\
\hline 11.15376 & 0.08909 & -0.34786 & -0.81181 & -0.10108 & -0.24777 & -0.10460 & -0.10902 \\
\hline 10.56571 & -0.10331 & -0.06817 & 0.03113 & 0.51685 & 0.20977 & -0.61483 & -0.22269 \\
\hline 7.96124 & 0.01573 & 0.01458 & -0.00766 & -0.16586 & -0.11023 & 0.35132 & 0.20771 \\
\hline 6.46192 & -0.01729 & -0.03351 & -0.00645 & -0.70801 & 0.02619 & -0.26190 & -0.01007 \\
\hline 0.02106 & 0.00533 & -0.01162 & -0.05582 & 0.40832 & -0.22226 & 0.47226 & 0.21457 \\
\hline 1.23478 & -0.01474 & 0.08333 & 0.23386 & -0.07053 & 0.29684 & -0.18847 & -0.08410 \\
\hline 1.88461 & -0.00868 & 0.03382 & 0.07196 & -0.00064 & 0.58039 & 0.19457 & 0.20597 \\
\hline 2.94878 & 0.00263 & -0.02231 & -0.05943 & 0.06047 & 0.09672 & 0.05279 & -0.02048 \\
\hline \multirow{2}{*}{ Eigenvalues } & \multicolumn{7}{|c|}{ Eigenvectors } \\
\hline & \multicolumn{2}{|c|}{ Bus 9} & Bus 10 & Bus 11 & Bus 12 & Bus 13 & Bus 14 \\
\hline 29.08193 & \multicolumn{2}{|c|}{-0.02319} & 0.07912 & 0.06818 & 0.17078 & -0.23886 & -0.07987 \\
\hline 21.80980 & \multicolumn{2}{|c|}{-0.00956} & 0.16378 & 0.15258 & 0.31691 & -0.52587 & -0.20917 \\
\hline 19.45788 & \multicolumn{2}{|c|}{-0.01900} & 0.15890 & 0.12761 & 0.26394 & -0.31206 & -0.08529 \\
\hline 15.81450 & \multicolumn{2}{|c|}{-0.04633} & 0.13268 & 0.07487 & 0.25257 & -0.27931 & -0.07489 \\
\hline 11.15376 & \multicolumn{2}{|c|}{-0.11149} & 0.33972 & -0.29429 & 0.29844 & 0.11904 & 0.08150 \\
\hline 10.56571 & \multicolumn{2}{|c|}{0.16039} & 0.25501 & 0.38718 & -0.07844 & 0.08730 & 0.11405 \\
\hline 7.96124 & \multicolumn{2}{|c|}{-0.23521} & 0.25641 & 0.57054 & -0.15396 & 0.26613 & 0.49053 \\
\hline 1.23478 & \multicolumn{2}{|c|}{-0.70805} & 0.33435 & -0.15233 & 0.14072 & 0.27871 & -0.33670 \\
\hline 1.88461 & \multicolumn{2}{|c|}{0.37176} & 0.34416 & -0.40090 & 0.41175 & 0.15842 & 0.29731 \\
\hline 2.58175 & \multicolumn{2}{|c|}{0.09961} & 0.34238 & -0.34550 & 0.29690 & 0.08081 & 0.23055 \\
\hline 2.94878 & \multicolumn{2}{|c|}{-0.17137} & 0.35950 & -0.12433 & -0.48937 & -0.48355 & 0.20816 \\
\hline
\end{tabular}

Table 11. Load flow analysis with STATCOM erected at bus 14 (Normal load).

\begin{tabular}{|c|c|c|c|c|c|c|}
\hline \multirow{2}{*}{ Bus No. } & \multirow{2}{*}{ Voltage (p.u.) } & \multirow{2}{*}{$\begin{array}{l}\text { Angle } \\
\text { Degree }\end{array}$} & \multicolumn{2}{|c|}{ Generation } & \multicolumn{2}{|c|}{ Load } \\
\hline & & & MW & MVAR & MW & MVAR \\
\hline 1 & 1.000 & 0 & 234.646 & -57.948 & 0 & 0 \\
\hline 2 & 1.000 & -5.8 & 40 & 62.334 & 21.7 & 12.7 \\
\hline 3 & 0.9700 & -14.5 & 0 & 34.873 & 94.2 & 19 \\
\hline 4 & 0.9597 & -11.6 & 0 & 0 & 47.8 & 0 \\
\hline 5 & 0.9843 & -10.0 & 0 & 0 & 7.6 & 1.6 \\
\hline 6 & 1.000 & -16.3 & 0 & 20.932 & 11.2 & 7.5 \\
\hline 7 & 0.9906 & -15.1 & 0 & 0 & 0 & 0 \\
\hline 8 & 1.000 & -15.1 & 0 & 5.332 & 0 & 0 \\
\hline 9 & 0.9863 & -16.9 & 0 & 0 & 29.5 & 16.6 \\
\hline 10 & 0.9808 & -17.1 & 0 & 0 & 9 & 5.8 \\
\hline 11 & 0.9866 & -16.9 & 0 & 0 & 3.5 & 1.8 \\
\hline 12 & 0.9889 & -17.3 & 0 & 0 & 6.1 & 1.6 \\
\hline 13 & 0.9880 & -17.6 & 0 & 0 & 13.5 & 5.8 \\
\hline 14 & 1.000 & -19.3 & 0 & 0 & 14.9 & 5 \\
\hline STATCOM & 1.0260 & -19.3 & 0 & 23.578 & 0 & 0 \\
\hline Total & & & 274.646 & 89.1 & 259 & 77.4 \\
\hline
\end{tabular}


In case of a single line outage, the total active power loss is increased with a maximum value of 1.03 times that at the base case, whereas the total reactive power loss is increased with a maximum value of 18 and a minimum of 5.53 times that at the base case.

Figures 5 and 6 show the active and reactive power losses in various cases of contingency.

The highest MVAR rating of STATCOM required to regulate the voltage at bus 14 to approximately 1 p.u. occurs in case of line 1 outage (starting at bus 1 and ending at bus 2). In this example, the highest values of active and reactive losses also correspond to the case of line 1 outage with a maximum device rating of 30.86 MVAR. Table 13 illustrates the voltage at bus 14 before and after locating STATCOM at bus 14 for various contingency cases.

In summary, a STATCOM of 30.86 MVAR rating, allocated at bus 14, leads to an acceptable voltage profile for both normal and contingency cases.

In the two studied systems, it was noticeable that only one eigenvalue has tended to approximately zero, and by allocating a suitable size STATCOM, the system operation has been secured. However, if more than one eigenvalue has a very small value (approaching zero), this will
Table 12. STATCOM rating with single line outage.

\begin{tabular}{cccc}
\hline From Bus & To Bus & Outage Line & STATCOM Rating (MVAR) \\
\hline 1 & 2 & Line 1 & 30.862 \\
1 & 5 & Line 2 & 26.161 \\
2 & 3 & Line 3 & 27.145 \\
2 & 4 & Line 4 & 27.69 \\
3 & 4 & Line 6 & 26.119 \\
3 & 4 & Line 6 & 23.895 \\
4 & 5 & Line 7 & 25.695 \\
4 & 7 & Line 8 & 25.55 \\
4 & 9 & Line 9 & 26.272 \\
5 & 6 & Line 10 & 28.436 \\
6 & 11 & Line 11 & 28.18 \\
6 & 12 & Line 12 & 24.472 \\
6 & 13 & Line 13 & 28.766 \\
7 & 8 & Line 14 & 28.128 \\
7 & 9 & Line 15 & 28.36 \\
9 & 10 & Line 16 & 23.622 \\
9 & 14 & Line 17 & 19.192 \\
10 & 11 & Line 18 & 24.317 \\
12 & 13 & Line 19 & 23.517 \\
13 & 14 & Line 20 & 20.552 \\
\hline
\end{tabular}

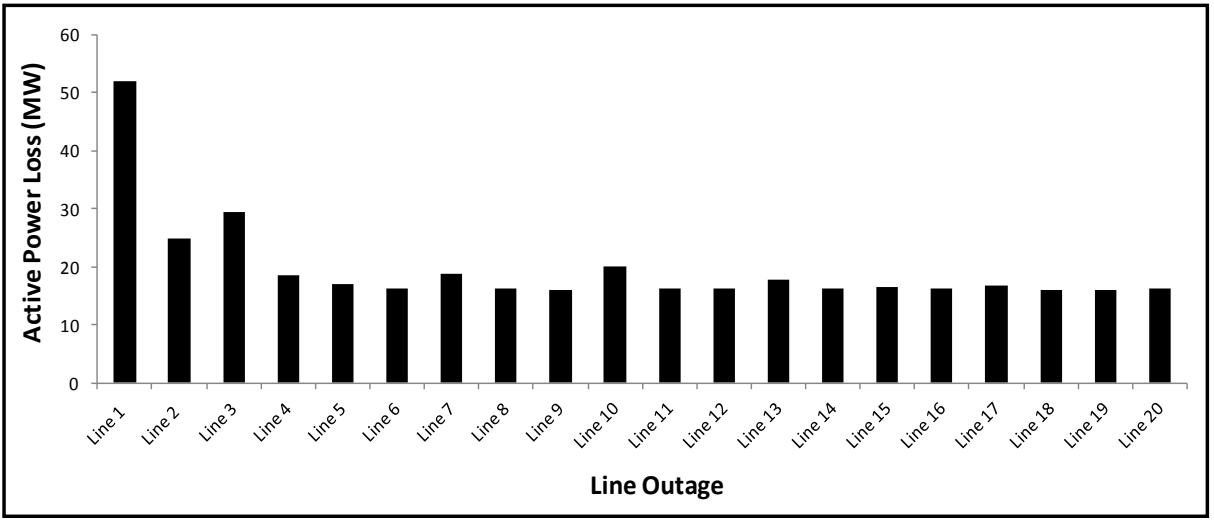

Figure 5. Active power loss with a single line outage.

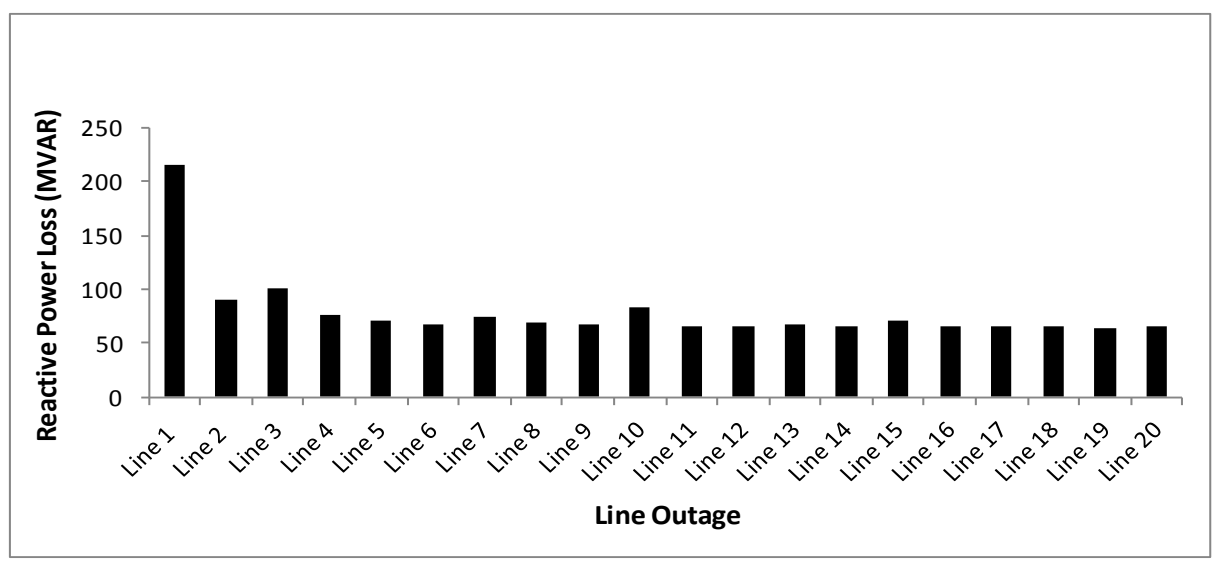

Figure 6. Reactive power loss with a single line outage. 
Table 13. Voltage magnitude at bus 14 with a single line outage for IEEE 14-bus system.

\begin{tabular}{|c|c|c|c|c|}
\hline From Bus & To Bus & Outage Line & $\begin{array}{c}\mathrm{V}_{14} \text { without } \\
\text { STATCOM } \\
\text { (p.u.) }\end{array}$ & $\begin{array}{l}\mathrm{V}_{14} \text { with } \\
\text { STATCOM } \\
\text { (p.u.) }\end{array}$ \\
\hline 1 & 2 & Line 1 & 0.9179 & 0.9959 \\
\hline 1 & 5 & Line 2 & 0.9316 & 1.0005 \\
\hline 2 & 3 & Line 3 & 0.9295 & 0.9995 \\
\hline 2 & 4 & Line 4 & 0.9273 & 0.999 \\
\hline 3 & 4 & Line 6 & 0.9316 & 1.0005 \\
\hline 3 & 4 & Line 6 & 0.9323 & 1.0027 \\
\hline 4 & 5 & Line 7 & 0.9328 & 1.0009 \\
\hline 4 & 7 & Line 8 & 0.9260 & 1.0011 \\
\hline 4 & 9 & Line 9 & 0.9226 & 1.0004 \\
\hline 5 & 6 & Line 10 & 0.9250 & 0.9983 \\
\hline 6 & 11 & Line 11 & 0.9344 & 1.0014 \\
\hline 6 & 12 & Line 12 & 0.9299 & 1.0021 \\
\hline 6 & 13 & Line 13 & 0.9089 & 0.9979 \\
\hline 7 & 8 & Line 14 & 0.9339 & 1.0088 \\
\hline 7 & 9 & Line 15 & 0.9005 & 0.9983 \\
\hline 9 & 10 & Line 16 & 0.9397 & 1.0029 \\
\hline 9 & 14 & Line 17 & 0.8876 & 1.0073 \\
\hline 10 & 11 & Line 18 & 0.9373 & 1.0023 \\
\hline 12 & 13 & Line 19 & 0.9330 & 1.003 \\
\hline 13 & 14 & Line 20 & 0.9204 & 1.0059 \\
\hline
\end{tabular}

indicate the presence of more than one suitable location for allocating the STATCOM. Further, if no solution can be achieved by locating one STATCOM, or the required capacity is too high, another device can be erected on the second preferable location determined by using the same procedure.

\section{Conclusion}

This paper presents a developed technique for sizing FACTS devices, namely the Static Synchronous Compensator (STATCOM). The paper considers cases of contingency aiming to improve the voltage profile of the system under these conditions. An algorithm is developed for this purpose to improve the static voltage stability by rescheduling reactive power control variables in case of contingency. The algorithm is based on the eigenvalues and eigenvectors of load flow Jacobian matrix using Newton Raphson technique for allocating STATCOM. A 5-bus system and IEEE 14-bus system models are both used to verify the validity of the proposed technique. The required STATCOM ratings, in both normal and contingency cases, are computed while the system operational constraints are still maintained to have a secured system. Consequently, the location and rating of
FACT device are obtained to maintain secure power system operation during both normal and contingency cases by controlling the reactive power of STATCOM according to various contingency cases. The obtained results verify the validity of the proposed technique in sizing the STATCOM.

\section{REFERENCES}

[1] N. G. Hingorani and L. Gyugi, "Understanding FACTSConcepts and Technology of Flexible AC Transmission System,” Wiley-IEEE Press, New York, 2000.

[2] S. Gerbex, R. Cherkaoui and A. J. Germond, "Optimal Location of Multi-type FACTS Devices in a Power System by Means of Genetic Algorithms,” IEEE Transactions on Power Systems, Vol. 16, No. 3, 2001 pp. 537544. http://dx.doi.org/10.1109/59.932292

[3] H. R. Baghaee, B. Vahidi, S. Jazebi, G. B. Gharehpetian and A. Kashefi, "Power System Security Improvement by Using Differential Evolution Algorithm Based FACTS Allocation," Joint International Conference on Power System Technology and IEEE Power India Conference, 2008, pp. 1-6.

[4] K. Morison, L. Wang and P. Kundur, "Power System Security Assessment," IEEE Power and Energy Magazine, Vol. 2, No. 5, 2004, pp. 30-39. http://dx.doi.org/10.1109/MPAE.2004.1338120

[5] M. Di Santo, A. Vaccaro, D. Villacci and E. Zimeo, “A Distributed Architecture for Online Power Systems Security Analysis," IEEE Transactions on Industrial Electronics, Vol. 51, No. 6, 2004, pp. 1238-1248. http://dx.doi.org/10.1109/TIE.2004.837862

[6] IEE/PES Power System Stability Subcommittee Special Publication, "Voltage Stability Assessment: Concepts, Practices and Tools,” Product No. SP101PSS, Final Document, 2002.

[7] N. K. Sharma, A. Ghosh and R. K. Verma, "A Novel Placement Strategy for FACTS Controllers,” IEEE Transactions on Power Delivery, Vol. 18, No. 3, 2003, pp. 982-987. http://dx.doi.org/10.1109/TPWRD.2003.813874

[8] R. Mingus, F. Milano, R. Zarate-Minano and A. J. Conejo, "Optimal Network Placement of SVC Devices," IEEE Transactions on Power Systems, Vol. 22, No. 4, 2007, pp. 1851-1860.

http://dx.doi.org/10.1109/TPWRS.2007.907543

[9] O. A. Oke, D. W. P. Thomas and G. M. Asher, "A New Probabilistic Load Flow Method for Systems with Wind Penetration” 2011 IEEE Conference on PowerTech, Trondheim, 19-23 June 2011, pp. 1-6.

[10] M. A. PAI, "Computer Techniques in Power System Analysis," 2nd Edition, McGraw Hill Publishing Company, New York, 2006.

[11] S. Kamel, M. Abdel-Akher and M. K. El-Nemr, "Hybrid Power and Current Mismatches Newton-Raphson LoadFlow Analysis for Solving Power Systems with Voltage Controlled Devices," Proceeding of the 14th International Middle East Power System Conference (MEPCON'10), Cairo, 19-21 December 2012, Paper ID 280. 
[12] N. Yorino, E. E. El-Araby, H. Sasaki and Sh. Harada, “A New Formulation for FACTS Allocation for Security Against Voltage Collapses,” IEEE Transactions on Power Systems, Vol. 18, No. 1, 2003, pp. 3-10. http://dx.doi.org/10.1109/TPWRS.2002.804921

[13] L. N. Giang, N. T. D. Thuy and T. T. Ngoat, “Assessment Study of STATCOM's Effectiveness in Improving Transient Stability for Power System,” TELKOMNIKA, Vol. 11, No. 10, 2013, pp. 6095-6104. http://dx.doi.org/10.11591/telkomnika.v11i10.2766

[14] S. Greene, et al., "Contingency Ranking for Voltage Collapse via Sensitivities from a Single Nose Curve," IEEE Transactions on Power System, Vol. 14, No. 1, 1999, pp. 232-238. http://dx.doi.org/10.1109/59.744538

[15] G. C. Ejebe, et al., "Methods for Contingency Screening and Ranking for Voltage Stability Analysis of Power Systems," IEEE Transactions on Power Systems, Vol. 11, No. 1, 1996, pp. 350-356. http://dx.doi.org/10.1109/59.486117

[16] E. Vaahedi, et al., "Voltage Stability Contingency Screening Ranking," IEEE Transactions on Power Systems, Vol. 14, No. 1, 1999, pp. 256-261. http://dx.doi.org/10.1109/59.744541

[17] M. Alinezhad and M. A. Kamarposhti, "Static Voltage Stability Assessment Considering the Power System Contingencies using Continuation Power Flow Method,” International Journal of Energy and Power Engineering, Vol. 3, No. 1, 2010, p. 6.

[18] L. T. Ha and T. K. Soha, "Investigation of Power Loss and Voltage Stability Limits for Large Wind Farm Connections to a Subtransmission Network," IEEE Power Engineering Society General Meeting, Denver, 6-10 June 2004, pp. 2251-2256.

[19] A. Chakrabarti, D. P. Kolhari and A. K. Mukhopadhyay, "Reactive Power Control and Voltage Stability in Power Transmission System,” PHI Private Limited, New Delhi, 2010.

[20] S. Halder and A. Chakrabarti, "Power System Analysis Operation and Control," Prentice-Hall of India Private Limited, New Delhi, 2006.

[21] Enrique Acha, et al., "FACTS, Modelling and Simulation in Power Networks," John Wiley \& Sons, New York, 2004. 


\section{APPENDIX A}

In contingency load flow, base power flow equations are reformulated by inserting a load parameter into these equations. In order to simulate the load change, a loading factor $\lambda$ is inserted into demand powers $P_{D_{i}}$ and $Q_{D_{i}}$ where:

$$
P_{D_{i}}=P_{D_{\text {io }}}+\lambda\left(P_{\text {bbase }}\right)
$$

$$
Q_{D_{i}}=Q_{D_{\text {io }}}+\lambda\left(Q_{\text {bbase }}\right)
$$

$P_{D_{\text {io }}}$ and $Q_{D_{\text {io }}}$ are the original load demands on the bus number $i$. $P_{\Delta \text { base }}$ and $Q_{\Delta \text { base }}$ are selected power quantities which are chosen to scale the loading factor $\lambda$ appropriately.

\section{APPENDIX B}

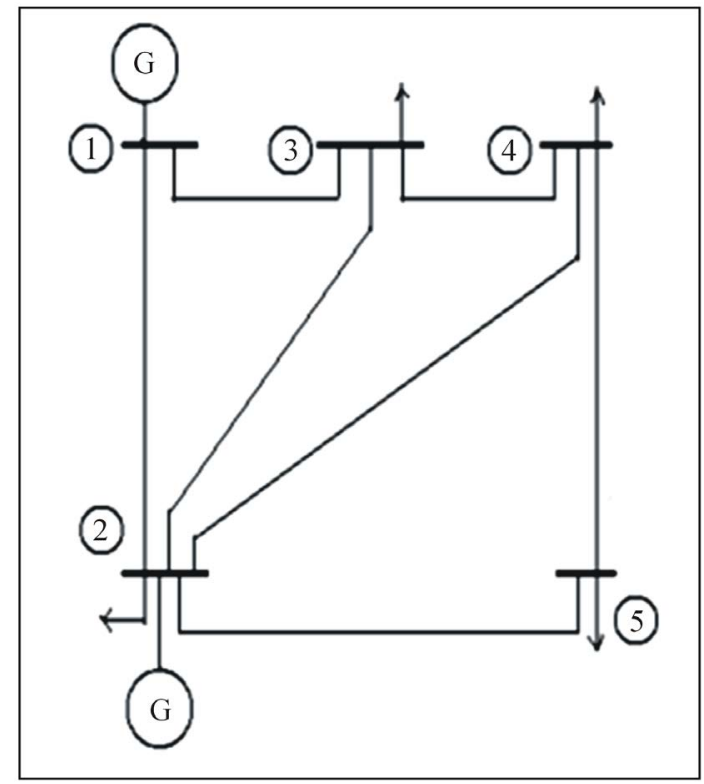

5-bus system model

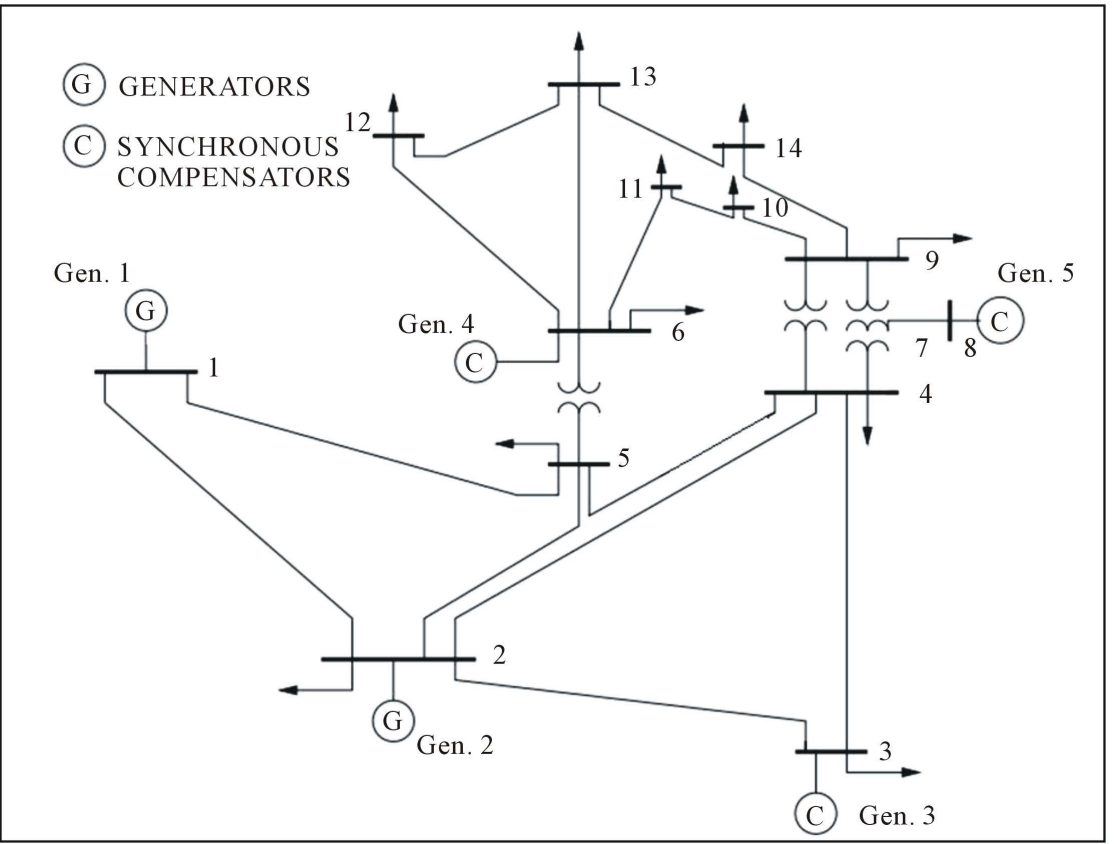

IEEE 14-bus system model 